\title{
Understanding Goal Setting Behavior in the Context of Energy Consumption Reduction
}

\author{
Michelle Scott, Mary Barreto, Filipe Quintal, and Ian Oakley \\ Madeira Interactive Technologies Institute, University of Madeira, Caminho da Penteada, \\ Funchal, 9020-105, Madeira, Portugal \\ \{mscott, fquintal\}@m-iti.org, \\ maryluizbarreto@gmail.com, ian@uma.pt
}

\begin{abstract}
Home energy use represents a significant proportion of total consumption. A growing research area is considering how to help everyday users consume less. However, simply determining how to best reduce consumption remains a challenging task for many users. Based on goal setting theory, this paper presents two lab studies (based on the presentation of detailed scenarios and the solicitation of goal selections for the individuals depicted) in order to better understand how users make such decisions. It reveals a preference for goals that are perceived to be easy and specific, rather than those known to be effective (e.g. those that reduce energy consumption) or generic. Goal setting theory suggests that easy goals lead to low levels of commitment and motivation, suggesting such choices may be doubly ineffective. Ultimately, this paper contributes to a better understanding of users' goal selections and argues this is a prerequisite to effectively supporting users in reducing resource consumption.
\end{abstract}

Keywords: Sustainability, Goal-Setting, Motivation, Energy Consumption.

\section{Introduction}

In the USA, energy consumption in private homes accounts for $22 \%$ of total use [14]. With increasing pressure placed on traditional sources and mechanisms of energy generation, there is growing interest in ways to reduce these levels. One way this can be achieved is via the design of interactive systems that encourage, support and motivate individual users to reduce their levels of consumption. Indeed, this is a rapidly developing research area in Human-Computer Interaction (HCI) covering topics as diverse as novel measurement systems [12], the design of sophisticated eco-feedback devices [6] and the exploration of how psychologically grounded theories of motivation and behavior change can best be adapted to leverage these rapid technological advances [7].

This paper extends this work. It explores how goal-setting theory, a psychological framework for understanding motivation and behavior change, can be applied to the task of reducing the home energy consumption of everyday users. Although there are numerous previous studies on this topic [e.g. 1, 10], this paper makes two main novel contributions. Firstly, we report data that supports goal setting theory within the 
specific domain of sustainability and within an interactive interface. Providing a domain specific validation of this theory will help generate effective new techniques for accurate, real-time capture of consumption activity and the development of advanced systems and interfaces for processing, storing and presenting this material. The second contribution relates to the notion that users have a poor understanding of how to set goals that result in significant changes to consumption levels [2]. We start to explore this idea in detail and show that people tend to pick easier goals for themselves, perhaps because they feel that others will choose difficult goals in their place. This has implications for the design of interactive systems since goal-setting theory posits that difficult goals are more effective motivators than easier goals. In this way, this paper contributes to our understanding of how people make sustainable goal choices, work that has direct application to the domain of HCI and sustainability.

This paper takes steps towards achieving these objectives. Specifically, it describes two studies exploring the nature of the goals users select in home energy reduction scenarios and the feasibility with which they regard them. The method used is a fast, economical and effective way to test theories in this domain and can be applied to other theoretical constructs. By casting light on user's perceptions of appropriate goals in this domain, this paper highlights possibilities for designing systems that encourage and support users in selecting appropriate goals.

\section{State of the Art}

Goal setting theory is an established and actionable framework for understanding how to motivate behavior change [8]. Fundamentally, it explores how the type and form of goals affect people's level of motivation and ability to achieve targets.

Two of the most important aspects within this framework are the challenge and clarity of goals. Studies have confirmed that difficult goals promote the highest levels of effort and performance as long as they are clearly expressed and criteria for successful achievement are well identified [3,8]. Vague goals, such as achieving optimal personal performance in some task, lack external reference and allow for a wide range of performance levels. Specificity decreases performance variability among users by reducing ambiguity with increasingly precise goals.

Other key factors affecting performance towards meeting goals include those that vary among individuals, such as self-efficacy (a measure of perceived empowerment), and goal commitment. People with higher self-efficacy choose more difficult goals for themselves than those with lower self-efficacy. They also have a higher commitment to achieving goals and are better at responding to negative feedback. Feedback is important for goals to be effective; feedback plus goals are more effective than goals alone [8].

Researchers have also applied goal-setting theory to consumption reduction scenarios. Becker [3] tested the effects of combined goal-setting and feedback on conservation behavior. Two groups of 40 households were either given electrical consumption feedback or not, three times a week. The two groups were also split into those with an easy $(2 \%)$ savings goal or a difficult $(20 \%)$ savings goal. The results showed that the difficult-goal-plus-feedback group was the only group that used significantly less (13\%) electricity. 
In contrast, McCalley [10], reported no difference in energy reduction for people who chose $5 \%$ and $20 \%$ goal levels in a task that gave immediate feedback on energy conserved using a washing machine simulation. Most people saved $20 \%$ compared to the control condition; this could suggest that self-set goals are more effective than imposed goals regardless of the goal level. Indeed evidence supports this assertion. For instance, the benefits of setting your own goal are cognitive rather than motivational. Autonomy in goal setting leads to setting higher challenges and having greater performance than when goals are assigned. Once you have chosen your own goal, you are also more committed to that goal [15].

Abrahamse [1] reinforced these points by indentifying the importance of supporting users in selecting personal, specific goals. They looked at integrating goal setting with tailored feedback about energy consumption. Participants received tailored recommendations via a website but their only goal was to reduce $5 \%$ of energy consumption. Feedback was given from their self-reports online after 2 and 5 months and households in the study ultimately saved $5.1 \%$ energy. This paper expands upon this work by allowing participants to choose their own goals from a set that includes options such as reducing consumption by percentages as well as more concrete goals such as using sleep mode on computers. Using self-chosen and more specific goals may be a more effective technique than setting abstract percentages. Finally, He et al. [7] suggested that adapting goals to specific situations and users is important in creating effective motivational systems.

In summary, this literature suggests that goal-setting theory has much to offer as an actionable framework for designing effective eco-feedback systems that motivate users to reduce consumption. Questions regarding how to select appropriate goals remain, in part due to the diversity of the literature on this topic and in part due to an undeveloped understanding of the basis with which users select goals in this domain [2]. The work in this paper attempts to address these issues via an experimental paradigm that allows users to choose goals with different levels of difficulty and specificity and provides instant feedback on these selections.

\section{Sustainable Goals Pilot Study}

This study explored how people select goals in order to reduce resource consumption in home scenarios. It builds on prior work suggesting that users typically select inappropriate or ineffective goals [2] and aims to more deeply understand the factors contributing to goal choice.

In order to do this, three scenarios depicting different home settings and lifestyles were developed. Scenarios were chosen because we felt it was more feasible within a lab setting compared to real time feedback. We argue that the use of such scenarios provides a mechanism for standardizing between participants, and is a simple and effective early-stage alternative to real system deployments that gather data about participants' current behaviors and household energy consumption. The scenarios were instantiated as narrated descriptions accompanied by illustrative sketches and produced in a video format. Table 1 highlights key aspects of the scenarios. A set of 11 unique goals was selected for each scenario (33 total). Goals were drawn from a literature review [e.g. 11] and sources such as the StepGreen social network [9]. 
A representative set of goals is also shown in Table 1. An additional criterion for goal selection was to include goals that varied on level of difficulty (easy/hard) and context (contextual/non-contextual) in each scenario. The easy/difficult categorization was validated using an online questionnaire.

Table 1. Scenario types and corresponding specific goals

\begin{tabular}{|c|c|c|c|}
\hline & High Income & Low Income & Single Woman \\
\hline Scenario Details & $\begin{array}{l}\text { Doctor and archi- } \\
\text { tect, } 1 \text { child, } 5 \text { bed } \\
\text { house, pool }\end{array}$ & $\begin{array}{l}\text { Janitor and super- } \\
\text { market clerk, } 3 \\
\text { children, } 3 \text { bed } \\
\text { house }\end{array}$ & $\begin{array}{l}\text { Lives alone, } 1 \text { bed } \\
\text { apt, career focused }\end{array}$ \\
\hline Specific Goals & $\begin{array}{l}\text { Don't heat pool in } \\
\text { summer. Turn off } \\
\text { lights and take } \\
\text { advantage of } \\
\text { sunlight. }\end{array}$ & $\begin{array}{l}\text { Repair leaky taps } \\
\text { quickly. Don't use } \\
\text { standby mode on } \\
\text { appliances. }\end{array}$ & $\begin{array}{l}\text { Use public transport } \\
\text { to get to work. Use } \\
\text { energy saving light } \\
\text { bulbs. }\end{array}$ \\
\hline
\end{tabular}

The questionnaire listed all 33 goals and asked participants to categorize each on a Likert scale spanning easy to difficult. 20 users completed the questionnaire. Of the 33 goals, two goals initially classified as difficult were perceived to be easy by subjects. After removing these from consideration Cronbach's alpha showed a high level of internal consistency of the remaining goals (difficult goals $=0.72$ over 9 goals in total). Similarly, two goals originally classified as easy were rated as difficult by participants. After removal of these, Cronbach's alpha showed the internal consistency of the remaining 20 goals to be high (easy goals $=0.86$ ).

In order to create contextual goals, the scenarios were written to include three contextual hints, which were directly related to three of the eleven goals available to choose for that scenario. For example, in the scenario involving the single woman, the narrated description stated that she used regular (non energy saving) light bulbs. Correspondingly, one of the contextual goals for this scenario was to use energy saving light bulbs. In the high-income family scenario, it was mentioned that they had a pool and one of the contextual goal choices for that scenario was to heat the pool less often to save energy. These goal choices were only available for those scenarios. On the other hand, non-contextual goals for each scenario did not relate to contextual detail provided within the scenarios. Illustrative examples of the goals used in the study can be seen in Table 1.

The main study used the three scenarios and 33 validated goals and was completed by 20 participants recruited via an email advertisement on a popular university forum and the snowball sampling method. Ages ranged from 20 to 34 with an average age of 26.5. 17 of the participants were male and 3 female. All were educated to the graduate level or above; 13 were in full time employment while the remaining 7 were students. Most of the sample was Portuguese (13), 3 were Indian and 1 each was Greek, Swedish, Taiwanese and Venezuelan. 13 were employed, 5 were students and 2 were unemployed. 18 were single and 2 were living with a partner. Household size ranged from 1 to 4 with an average size of 2.65 , household income ranged from $€ 10,000$ to 
$€ 48,000$ with an average household income of approximately $€ 27,500$. Participants were given $€ 5$ compensation for their time.

The experiment started by capturing a baseline measure of environmental concern, a simple questionnaire was developed. The level of overall environmental concern was calculated as the mean of three items measured on five point Likert scales. An analysis of the data captured during the studies conducted in this paper indicated this simple measurement tool exhibited a high level of internal consistency (Cronbach's alpha test reporting 0.79). The three items were as follows:

In your opinion, how serious (severe) is global warming? (Likert scale labels from 'Not serious' to 'Very serious')

I feel my energy consumption is something I... ('Don't need to worry about' to 'Do need to worry about')

I feel worried about the possible effects of global warming. ('Not at all worried' to 'Extremely worried')

Participants then moved to a computer interface (built using Adobe AIR) where they were then exposed to the three scenarios in a fully balanced Latin square design three participants experienced each of the six possible presentation orders. Directly after watching each video, participants were asked to select goals from the validated list that would best enable the depicted family to reduce their resource consumption. They were provided with immediate feedback on the effectiveness of the goals using a range of typically non-homogeneous metrics (e.g. money saved, or impact on carbon footprint). After selecting four goals per scenario, they were asked to rate whether or not they believed that the goals were realistic by rating whether or not the family described in the scenario would achieve it. They were asked the following for each goal chosen:

"How often do you think the family would commit to each of the following goals you have just chosen?"

The four goals were presented with a Likert scale with the points labeled: Rarely/Never, Occasionally, About half the time, Frequently and Almost Always/Always. Finally, after completing this process for all three scenarios, the experiment closed by asking participants to report how often they engaged in the activities implied by the goals used in the study. This questionnaire included all of the thirty-three goals that had been presented in the interface previously in random order. Participants were asked:

"How often do you perform each of the following energy-saving behaviors when you are in your home? Please select not applicable (N/A) if you do not own an item."

These items were presented with the same Likert scale as previously, including the point "Not applicable". Any "Not applicable" answers were excluded from the analysis. Adding up scores from the final questionnaire created a measure of sustainable lifestyle, higher scores indicating higher current sustainable behaviors. This last measure was intended to separate out what participants felt to be ideal goals, from those that they felt to be realistic goals. This is an interesting comparison to make as people can make different choices for others than they do for themselves. In total, the experiment lasted approximately 25 minutes. 
Table 2. Most popular goals chosen for households in the scenarios and selves, means and corresponding standard deviations shown in parentheses. ${ }^{*}$ S Significant at the .01 level * significant at the .05 level.

\begin{tabular}{|c|c|c|c|c|c|}
\hline & $\begin{array}{c}\text { Selected } \\
\text { for others }\end{array}$ & $\begin{array}{c}\text { Self } \\
\text { performs }\end{array}$ & $\begin{array}{c}\text { Mean rating } \\
\text { of how often } \\
\text { others } \\
\text { perform }\end{array}$ & $\begin{array}{c}\text { Mean rating } \\
\text { of how often } \\
\text { self performs }\end{array}$ & $\begin{array}{c}\text { Feedback } \\
\text { over year }\end{array}$ \\
\hline $\begin{array}{c}\text { Use public transport } \\
\text { to get to work }\end{array}$ & $72.2 \%$ & $33.3 \%$ & $3.23(0.83)$ & $1.46(1.76)^{* *}$ & $€ 104$ saved \\
\hline $\begin{array}{c}\text { Turn off lights and } \\
\text { take advantage of } \\
\text { sunlight }\end{array}$ & $72.2 \%$ & $88.9 \%$ & $3.62(1.12)$ & $4.38(1.12)$ & $€ 38$ saved \\
\hline $\begin{array}{c}\text { Turn off lights when } \\
\text { not in the room }\end{array}$ & $72.2 \%$ & $100 \%$ & $4.54(0.66)$ & $4.69(0.48)$ & $€ 6$ saved \\
\hline $\begin{array}{c}\text { Turn off water when } \\
\text { not using }\end{array}$ & $72.2 \%$ & $100 \%$ & $4.31(0.95)$ & $4.92(0.28)$ & $€ 145$ saved \\
\hline
\end{tabular}

The study was designed with an exploratory analysis in mind. The overarching goal was to cast light on the types of goals people select, with the expectation that there would be tradeoffs between easy and hard goals and goals that are known to be effective and ineffective. Two formal hypotheses were also generated. The first hypothesis is novel in the sustainability domain and relates to goal context. The second serves to check on internal consistency of the experimental setup and determine whether participants were accurately reporting their attitudes and actions. The hypotheses were:

H1: Contextual goals will be chosen more frequently within the consumption reduction scenarios than non-contextual goals.

H2: Environmental concern will be positively correlated with self-report of engaging more frequently in sustainable behaviors.

\subsection{Results}

Table 2 shows the most popular goals chosen for each of the three scenarios, including the information presented to participants about projected savings. Participant's self-report of their own behavior is also shown, as is their assessment of whether or not the individuals depicted in the scenarios would adopt the goals.

The least popular goals chosen for the scenarios, along with corresponding feedback are presented below, with the amount of times each was selected is shown in parentheses:

Use energy saving light bulbs - €27 saved (1)

Eat lunch at home once or twice a week - save on petrol costs and cut emissions (1)

Save 5 Euros from your bill a month - €60 saved (0) 
Hypothesis 1 was supported. Goals were coded as either 1 for chosen or 0 for not chosen and means calculated. A t-test $(\mathrm{t}(17)=3.12, \mathrm{p}<0.01)$ showed participants selected goals classified as contextual (Mean $=0.44, \mathrm{SD}=0.10$ ) over those goals classified as non-contextual (Mean $=0.32, \mathrm{SD}=0.06)$. A second t-test $(\mathrm{t}(17)=2.40$, $\mathrm{p}<0.05)$ revealed participants selected easy goals (Mean $=0.41, \mathrm{SD}=0.07$ ) over those rated as difficult $($ Mean $=0.28, \mathrm{SD}=0.16)$. The top 4 most popular goals shown in Table 2 were all classified as easy goals.

Hypothesis 2 was also supported. The sum of the participants' ratings of how often they engaged in the goals used in the study was calculated as a measure of the sustainability of their lifestyles. This was strongly correlated with the level of environmental concern (Pearson's $r=0.53, \mathrm{n}=18, \mathrm{p}<0.05$ ). The sum of participants' ratings of how often they engaged in the goals that were classed as difficult was also calculated as a measure of their sustainable lifestyles. The level of environmental concern also correlated strongly with the difficult sustainable behaviors that participants reported they performed $(r=0.62, \mathrm{n}=18, \mathrm{p}<0.01)$.

Differences between users recommendations of goals for others and their willingness to adopt them personally are clear in this data. In particular, public transportation was recommended for those depicted in the scenarios much more frequently that it was reported to be personally suitable - a t-test showed this difference to be significant ( $\mathrm{t}$ $(12)=-3.18, p<0.01)$. In contrast, participants reported themselves more willing to rely on sunlight (as opposed to artificial light) than individuals in the scenarios, this result approached significance $(\mathrm{t}(12)=1.87, \mathrm{p}=0.08)$. A similar non-significant trend emerged in ratings for turning off water whilst not in use $(t(12)=2.13, p=0.06)$. The means and standard deviations for these t-tests are shown in Table 2.

\subsection{Discussion}

The first finding is the firm support for the hypothesis that people prefer contextual goals to non-contextual ones. Contextual goals are more actionable and are thus more likely to be carried out. The selection of more contextual goals over non-contextual ones shows that people need accurate, relevant and contextualized information when they are choosing goals. Providing information that relates to users specific behaviors and the contexts in which they happen will allow them to select more appropriate goals and ultimately better motivate users towards reducing consumption.

The results also indicate that people are poor at selecting optimal goals in this domain. The second and third most popular goals selected related to home lighting and were easy to accomplish but have little measureable impact. This suggests that people select goals based on the ease with which they can be achieved and seamlessly integrated into their routines and lifestyles. People seem to be more aware of the existence of easier goals and think that they are a fast way to make effective changes and be more sustainable. However, such goals are highly problematic. Not only do they have very limited impact on energy consumption, but the ease with which they can be achieved can lead to reduced levels of motivation [8].

Another finding in this study is that users pick different goals for others than they do for themselves. Furthermore, they overestimate the willingness of others to adopt them. 
As shown in Table 2, the public transportation goal was the most popular chosen for the individuals depicted in the scenarios, with participants estimating that this would be performed around half the time. However, when the same people were asked how often they performed this activity, a significantly lower rating was recorded.

Finally, perhaps unsurprisingly, higher levels of environmental concern translated into the adoption of more difficult goals; this could be due to the fact that people with higher levels are aware of the impact of their particular behaviors.

\section{Follow Up Goal Setting Study}

\subsection{Method}

A larger second study was conducted in order to build on the findings from the pilot study. It used the same scenarios approach as in the pilot. However, this study did revise several methodological shortcomings present the pilot.

The number of goals was reduced from thirty-three in the pilot to twelve in the second study. Instead of presenting eleven different goals in each scenario, the same twelve goals were presented in each scenario. This enabled a more direct comparison between scenarios. The scenarios were presented to participants in a random order to control for practice and habituation effects.

The goals were selected in order to cover a broad range of behaviors. From the thirty-three used in the pilot, the twelve in the current study were chosen to include an equal number of easy/difficult goals and of vague/specific goals. Validation of goals in the easy/difficult categorization was completed during in the pilot. A similar validation for vague/specific goals was performed as part of this study. This took the form of an online questionnaire in which participants rated the goals on a Likert scale. The scale was scored with the following terms: very vague; somewhat vague; neither vague nor specific; somewhat specific; and very specific. After performing this validation, 12 goals were selected such that three goals fell in to the category pairs of easy/specific, three in easy/general, three in difficult/specific and three in difficult/general. Cronbach's alpha reported the internal consistency of the specific goals as .78 and of vague goals as .70. The final goal list is shown in Table 3.

A significant change from the pilot was the removal of goals that were contextual within the individual scenarios. This addressed one of the methodological issues with the pilot: that contextual goals in each scenario might serve as a confound with the overall, scenario-independent level of specificity of the goals.

33 participants completed the study online. They were recruited via online advertisements for participants on Facebook, via email lists and through an online study website. Participants were not compensated for their time. Ages ranged from 16 to 63 with an average age of 30.5. There were 12 males and 20 females, with one person choosing not to report their gender. Just over half of the sample (17) was educated to degree level or above, 10 people had completed high school and 5 people had completed some college, 1 did not report their education. 16 participants were employed, 13 were students, 3 were unemployed and 1 was retired. Most of the sample were Portuguese (18), 7 were from the U.S.A., 3 were from the U.K. and 1 each were from 
Romania and India with the remaining 3 choosing not to report nationality. The majority of the sample was single (22), 6 were married, 2 were living with a partner and 1 was divorced. The household size ranged from 1 to 8 with a mean size of 3 and household income ranged from $€ 12,000$ to $€ 250,000$ with a mean of approximately $€ 55,000$. All participants had Internet access at home.

Table 3. Goal list with levels of difficulty and specificity

\begin{tabular}{|l|l|l|}
\hline Goal & Specificity & Difficulty \\
\hline $\begin{array}{l}\text { Save a percentage of your energy bill } \\
\text { over time }\end{array}$ & Vague & Easy \\
\hline Reduce carbon footprint & Vague & Easy \\
\hline Do more outdoor activities & Vague & Easy \\
\hline Save the environment & Vague & Difficult \\
\hline $\begin{array}{l}\text { Take part in a local environmental or- } \\
\text { ganization }\end{array}$ & Vague & Difficult \\
\hline $\begin{array}{l}\text { Compete with neighbor to be more sus- } \\
\text { tainable }\end{array}$ & Vague & Difficult \\
\hline $\begin{array}{l}\text { Switch off appliances/lights when not in } \\
\text { the room }\end{array}$ & Specific & Easy \\
\hline Turn off water when not using it & Specific & Easy \\
\hline $\begin{array}{l}\text { Wash full loads only and where possible } \\
\text { at } 30 \text { degrees Celsius }\end{array}$ & Specific & Easy \\
\hline Use public transport & Specific & Difficult \\
\hline Replace old large kitchen appliances & Specific & Difficult \\
\hline Become vegetarian & Specific & Difficult \\
\hline
\end{tabular}

The experiment began by asking for demographic information including basic details about a participant's household, such as size and income. A baseline measure of environmental concern was then collected. This was achieved with the New Ecological Paradigm [5], a well-established 15-item measure intended for this purpose. Each item is measured on a 5-point Likert scale and an overall score of environmental concern is derived from the mean of pro-environmental responses.

Participants were then presented with the scenarios used in the pilot study (the high-income family, the low-income family and the single woman) in a random order. The list of 12 goals was presented after each scenario video. When the participant moused over a goal, feedback on the effectiveness popped up for that goal. Feedback was as accurate as possible and the majority was derived from content and tools available on the Stepgreen.org website [9]. Other statistics were taken from trusted sources such as the US Department of Water. Participants were then asked to select three goals from the list of 12 that they felt would enable the family presented in the scenario to reduce their resource consumption. After selecting three goals, they were 
taken to the next screen, which showed a summary of the goals chosen with the appropriate feedback for each goal. The participants were then asked:

"How often do you think the family would commit to each of the following goals you have just chosen?"

For each of the three goals chosen, participants had to choose from a 5-item Likert scale with the items: Rarely/Never; Occasionally; About half the time; Frequently and Almost always/Always. This was repeated for three times for each scenario. After the scenarios were completed, participants were again presented with the list of 12 goals and asked:

"How often would you commit to each of the following goals?"

This item was scored exactly as the item above. We asked participants in an openended question if they would like to add any more goals/activities that they currently do. The study ended with a well-established 10-item measure of self-efficacy [13].

The experimental hypotheses were as follows:

H1: Participants will choose specific/easy goals more often than vague/difficult goals within the scenarios and will also rate themselves as more likely to commit to specific/easy goals compared to vague/difficult goals.

H2: Participants will choose easy goals for themselves even though they receive feedback that shows they are ineffective goals.

H3: Participants will rate others' commitment to goals as higher than their own.

\subsection{Results}

The first hypothesis was supported. More people chose specific goals for others within the scenarios than vague goals. This result was significant $(\mathrm{t}(32)=6.87, \mathrm{p}<0.001)$; means and standard errors are shown in Figure 1. This supports goal setting theory, which states that people prefer specific goals to vague ones. The results show that more people chose easy goals for others rather than difficult ones. This result was also significant $(\mathrm{t}(32)=5.61, \mathrm{p}<0.001)$; means and standard errors are shown in Figure 1.

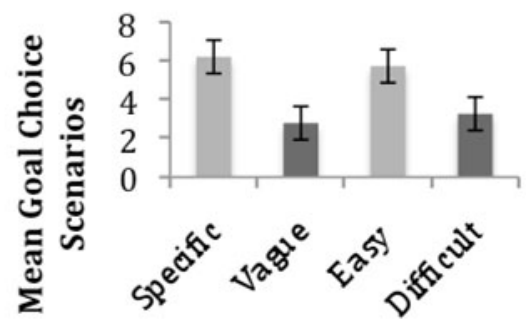

Goal Type

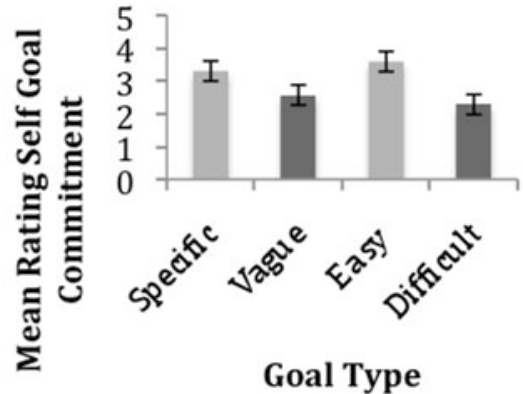

Goal Type

Fig. 1. On the left: Mean goal choices for others in scenarios by goal type (maximum 9). On the right: Mean rating of own commitment by goal type (scale maximum 5). Standard errors are also shown. 
Participants also rated themselves as more likely to commit to specific goals than vague goals. This was a significant result $(\mathrm{t}(32)=6.98, \mathrm{p}<0.001)$ as shown in Figure 1. There was also a significant difference $(\mathrm{t}(32)=10.37, \mathrm{p}<0.001)$ in how often they thought they would commit to easy goals compared to difficult goals (see Figure 1).

Table 4 shows the list of goals in order of popularity over all the three scenarios. The maximum possible for each goal is 99 , where each of the 33 participants chose

Table 4. Goal list by scenario popularity. Goal type and feedback presented are also shown.

\begin{tabular}{|c|c|c|c|}
\hline Goal & $\begin{array}{l}\text { Amount } \\
\text { chosen }\end{array}$ & $\begin{array}{l}\text { Goal } \\
\text { Type }\end{array}$ & Feedback \\
\hline $\begin{array}{l}\text { Use public transport to } \\
\text { get to work }\end{array}$ & 55 & $\begin{array}{l}\text { Specific } \\
\text { Difficult }\end{array}$ & $\begin{array}{l}\text { This could save } € 104 \text { a year, assuming } € 10 \\
\text { a week spent on petrol replaced with } € 2 \\
\text { bus costs a day }\end{array}$ \\
\hline $\begin{array}{l}\text { Switch off appliances or } \\
\text { lights when not in the } \\
\text { room }\end{array}$ & 50 & $\begin{array}{l}\text { Specific } \\
\text { Easy }\end{array}$ & Save $€ 12$ yearly and 80 kilos of $\mathrm{CO} 2$ \\
\hline Wash full loads at $30 \mathrm{C}$ & 48 & $\begin{array}{l}\text { Specific } \\
\text { Easy }\end{array}$ & $\begin{array}{l}\text { This could save } € 13 \text { and } 71 \text { kilos of } \mathrm{CO} 2 \text { a } \\
\text { year }\end{array}$ \\
\hline $\begin{array}{l}\text { Save a percentage of } \\
\text { energy consumption or } \\
\text { money over time }\end{array}$ & 30 & $\begin{array}{l}\text { Vague } \\
\text { Easy }\end{array}$ & $\begin{array}{l}\text { This could save you e.g., } 10 \% \text { from your } \\
\text { monthly bill }\end{array}$ \\
\hline $\begin{array}{l}\text { Turn off water when not } \\
\text { using it }\end{array}$ & 27 & $\begin{array}{l}\text { Specific } \\
\text { Easy }\end{array}$ & $\begin{array}{l}\text { This would save } € 145 \text { yearly and } 11,000 \\
\text { liters of water }\end{array}$ \\
\hline $\begin{array}{l}\text { Do more outdoor } \\
\text { activities }\end{array}$ & 25 & $\begin{array}{l}\text { Vague } \\
\text { Easy }\end{array}$ & $\begin{array}{l}\text { Benefit your health, more fresh air and } \\
\text { outdoor activities can help prevent } \\
\text { diseases and prolong your life }\end{array}$ \\
\hline $\begin{array}{l}\text { Replace old large } \\
\text { kitchen appliances with } \\
\text { new energy efficient } \\
\text { ones }\end{array}$ & 18 & $\begin{array}{l}\text { Specific } \\
\text { Difficult }\end{array}$ & $\begin{array}{l}\text { The initial investment of new appliance } \\
\text { will be recovered within } 3 \text { years }\end{array}$ \\
\hline Reduce carbon footprint & 12 & $\begin{array}{l}\text { Vague } \\
\text { Easy }\end{array}$ & $\begin{array}{l}\text { A collection of several different types of } \\
\text { actions, the result would be better for the } \\
\text { planet and our natural resources }\end{array}$ \\
\hline $\begin{array}{l}\text { Compete with neighbor } \\
\text { to be more sustainable }\end{array}$ & 12 & $\begin{array}{l}\text { Vague } \\
\text { Difficult }\end{array}$ & $\begin{array}{l}\text { For example, installing a solar panel, this } \\
\text { would give you free power for } 20 \text { years } \\
\text { after the initial cost }\end{array}$ \\
\hline Save the environment & 9 & $\begin{array}{l}\text { Vague } \\
\text { Difficult }\end{array}$ & $\begin{array}{l}\text { Think about future generations and a } \\
\text { better living environment for everyone }\end{array}$ \\
\hline $\begin{array}{l}\text { Take part in a local } \\
\text { environmental organiza- } \\
\text { tion }\end{array}$ & 7 & $\begin{array}{l}\text { Vague } \\
\text { Difficult }\end{array}$ & $\begin{array}{l}\text { You will get some exercise and fresh air } \\
\text { and contribute positively to your } \\
\text { community }\end{array}$ \\
\hline Be vegetarian & 7 & $\begin{array}{l}\text { Specific } \\
\text { Difficult }\end{array}$ & $\begin{array}{l}\text { It's one of the most effective steps you can } \\
\text { take and it can save } 1600 \text { kilos of CO2 a } \\
\text { year }\end{array}$ \\
\hline
\end{tabular}


that goal in each of the three scenarios. As can be seen in the table, most of the specific and easy goals are in the top half of the table, as predicted. People prefer goals that are specific, supporting goal setting theory. Feedback for each of the goals is also shown in the table. Two of the most popular goals: switching off appliances and washing full loads of clothes at 30 degrees Celsius, are two of the least effective. These goals save around $€ 1$ a month but they were chosen, on average, by half the participants per scenario. This supports our second hypothesis.

There were some small differences in the most popular goals by scenario. In the high-income scenario, the most popular goals were: wash full loads at 30 degrees Celsius (chosen by 21 of 33 participants), switch off appliances (20 out of 33 participants) and use public transport (17 out of 33). In the low-income scenario, the most popular goals were: use public transportation (14 out of 33), turn off appliances, turn off water and do more outdoor activities were all chosen 13 times. In the single woman scenario, the most popular goals were: use public transportation (24 out of 33 ), wash full loads at 30 degrees Celsius (23 out of 33) and turn off appliances (17 out of 33 ).

Our third hypothesis was not supported. There were some differences between ratings of how often others would commit to a goal compared to how often the self would commit to a goal. In contrast what was expected and to the findings in the pilot, participants rated themselves as more likely to commit to using public transportation (Mean $=3.18, \mathrm{SD}=1.78$ ) compared to others $($ Mean $=1.76, \mathrm{SD}=1.03)$. This was a significant result $(\mathrm{t}(16)=-3.67, \mathrm{p}<0.01)$. They also rated themselves as more likely to commit to switch off water when it is not being used (Mean $=4.54, \mathrm{SD}=$ $0.78)$ than others $($ Mean $=0.85, \mathrm{SD}=1.73)$. This was a significant difference $(\mathrm{t}(12)=$ $-7.22, \mathrm{p}<0.001)$. Participants also rated themselves as significantly $(\mathrm{t}(16)=2.28, \mathrm{p}<$ 0.05 ) more likely to commit to switching off appliances (Mean $=4.41, \mathrm{SD}=0.51$ ) that are not in use compared to others $($ Mean $=3.82, \mathrm{SD}=1.01)$.

Once again there was no significant correlation found between self-efficacy and goal type chosen for others or between self-efficacy and ratings of participant commitment to goal type. Higher self-efficacy was expected to correlate with more difficult goal choices, but this was not found.

There were also no significant correlations found between scores on the New Ecological Paradigm (NEP), a measure of pro-environmental orientation, and types of goal choice for others, or between the NEP and ratings of self-commitment to goals.

\subsection{Discussion}

Our main study showed full support for our first hypothesis. Participants chose specific and easy goals within the scenarios more often than they chose difficult and vague goals. This confirms the results from the pilot study and also confirms goal setting theory, which states that participants prefer specific goals, as they are more actionable than vague goals. The least popular goal was: be vegetarian. Even though it is a specific goal, this is probably due to that fact that it is too difficult for most people to commit to.

People also indicated they would personally commit more to specific goals rather than vague goals, supporting goal setting theory. The data also showed they would commit more often to easy goals rather than difficult goals, extending the findings 
from the pilot. One possible explanation is that difficult goals may be too much of a long-term commitment for people, while easy goals can be rapidly integrated into a person's everyday activities. For instance, both doing more outdoor activities, and taking part in a local environmental organization have clear real world parallels. However, doing more outdoor activities was rated as an easier goal, possibly because it is perceived to be more under a person's direct control than joining an organization. Actionable and effective recommendations are needed for people to choose appropriate sustainable behaviors.

Our second hypothesis was also supported. The two least effective goals in terms of money and $\mathrm{CO} 2$ savings were the second and third most popular choices. However, goal setting theory states that difficult and specific goals produce the greatest results. This finding has implications for encouraging behavior change regarding sustainable activities. Easy goals such as turning off appliances or lights tend to be the ones people know most about. People therefore need be provided with more information about effective goals, perhaps presenting more difficult goals or actions in terms of smaller steps that can encourage more effective behavior change over time.

Using public transportation to get to work was the most popular goal and is much more effective than the next two goals in popularity for the scenarios. People need concrete, effective recommendations if they are to make sustainable informed choices about their lifestyle.

There was no support found for our third hypothesis. We expected to see a difference between ratings of commitment to goals between the self and others. There was a difference found but not in the direction expected. More people rated their own commitment to some goals as higher than others' commitment to goals. This is different from the results in the pilot, which suggested that people would choose more difficult goals for others than for themselves. However, the wording of the question was different in the main study: we asked how often participants would be willing to commit to goals, whereas in the pilot we asked about the current behaviors. Our interpretation of this result is that people are more honest when asked about current behaviors and overestimate about their future plans. However, this discrepancy could also be due to differences in the samples; our second sample was broader (and somewhat older) than our first, so they could simply be more aware of the changes they are able to enact in their lives. Further work needs to be done in this area to determine the extent to which people think others will shoulder the responsibility for sustainable energy use.

\section{Conclusion}

This paper presented two main contributions. Firstly, our studies found support for goal setting theory within the domain of sustainability. Both the pilot and the main study showed that people prefer specific or contextual goals to vague or noncontextual ones. The second contribution shows that users have a poor understanding of how to set goals that have a significant effect on energy consumption levels. Both studies showed that people tend to pick easier goals for themselves, perhaps because they feel that others will choose difficult goals in their place. Since goal setting theory 
states that more difficult goals are more effective at getting real results, this has implications for the design of interactive systems.

Previous discussions of goal setting theory have typically been based on aggregate consumption data shown using simple numerical displays [e.g. 10]. While considerable benefits have been shown in this work, this paper argues that additional benefits will emerge through appropriately designed techniques based upon the theory and in the field and would use real-time contextualized feedback [6]. Participants would be able to choose their own goals and receive feedback based on detailed disaggregated data representing consumption practices [4] from their home. They would be presented with customized information and personalized recommendations [7] based on the goals chosen and feedback received. This system would not be annoying, intrusive or repetitive and would adapt to users needs as required. This paper takes steps towards the first design of such a system by showing how users choose goals, the types of goals they choose for themselves and makes an attempt to understand the reason for these choices. This will lead to further work, such as a system based in people's homes, which collects their energy data, allows self-set goals and gives contextualized feedback based on this. The type of goal setting interface utilized in this paper can be used to test theories cheaply and easily. It is quicker than implementing a working system in the field and can be used as a first step to designing useful systems that can have an impact on encouraging sustainable behavior change.

Options for future work on this topic are broad. A key development would be to integrate further work exploring goal selection with real-time sensing and presentation of home energy consumption levels. This will allow the development of interfaces that provide tailored, actionable and contextually relevant goals to users. Regularly updated feedback would also offer users confirmation of the effectiveness of their actions and goals. In summary, this paper has highlighted the need to better understand goal selection behavior in the context of consumption reduction scenarios, so that users can be guided towards more effective and efficient goal selections. Ultimately, this paper suggests that developing a better understanding of users goals will allow the design of better systems to reduce energy consumption.

\section{References}

1. Abrahamse, W., Steg, L., Vlek, C., Rothengatter, T.: The effect of tailored information, goal setting, and tailored feedback on household energy use, energy-related behaviors, and behavioral antecedents. Journal of Environmental Psychology 27, 265-276 (2007)

2. Attari, S.Z., DeKay, M.L., Davidson, C., de Bruin, W.B.: Public perceptions of energy consumption and savings. Procs. of the National Academy of Sciences of the United States of America 107, 1-6 (2010)

3. Becker, L.J.: Joint effect of feedback and goal setting on performance: A field study of residential energy conservation. Journal of Applied Psychology 63(4), 428-433 (1978)

4. Berges, M., Matthews, H.S., Soibelman, L.: A System for disaggregating Residential Electricity Consumption by Appliance. In: The IEEE International Symposium on Sustainable Systems and Technology (ISSST), Washington, DC (2010)

5. Dunlap, R.E., Van Liere, K.D., Mertig, A.G., Jones, R.E.: Measuring Endorsement of the New Ecological Paradigm: A Revised NEP Scale. Journal of Social Issues 56(3), 425-442 (2000) 
6. Froehlich, J., Findlater, L., Landay, J.: The Design of Eco-Feedback Technology. In: Proceedings of CHI 2010, Atlanta, Georgia, USA (2010)

7. He, H.A., Greenberg, S., Huang, M.E.: One size does not fit all: applying the Transtheoretical Model to Energy Feedback Technology Design. In: CHI 2010: Sense and Sustainability, pp. 927-936. ACM Press, New York (2010)

8. Locke, E.A., Latham, G.P.: Building a Practically Useful Theory of Goal Setting and Task Motivation. American Psychologist 57(9), 705-717 (2001)

9. Mankoff, J., Fussell, S.R., Dillahunt, T., Glaves, R., Grevet, C., Johnson, M., Matthews, D., Matthews, H.S., McGuire, R., Thompson, R.: Stepgreen.org: Increasing Energy Saving Behaviors via Social Networks. In: ICWSM 2010 (2010)

10. McCalley, L.T., Midden, J.H.: Energy conservation through product-integrated feedback: The roles of goal-setting and social orientation. Journal of Economic Psychology, 589-603 (2002)

11. Osbaldiston, R., Sheldon, K.M.: Promoting internalized motivation for environmentally responsible behavior: a prospective study of environmental goals. Journal of Env. Psychology 23, 349-357 (2003)

12. Patel, S.N., Gupta, S., Reynolds, M.: The Design and Evaluation of an End-User Deployable, Whole House, Contactless Power Consumption Sensor. In: Proceedings of CHI 2010, Atlanta, Georgia, USA (2010)

13. Schwarzer, R., Jerusalem, M.: Generalized Self-Efficacy scale. In: Weinman, J., Wright, S., Johnston, M. (eds.) Measures in Health Psychology: A User's Portfolio. Causal and Control Beliefs, pp. 35-37. NFER-NELSON, Windsor (1995)

14. U.S. Department of Energy. Annual Energy Review 2009. Energy Information Administration, Washington, DC, DOE/EIA-038 (2010)

15. Wright, P.M., Kacmar, K.M.: Goal Specificity as a Determinant of Goal Commitment and Goal Change. Organizational Behavior and Human Decision Processes 59(2), 242-260 (1994) 